\title{
Development of affective modelling competencies in primary school learners
}

\author{
Authors: \\ Piera Biccard ${ }^{1}$ \\ Dirk Wessels ${ }^{1}$ \\ Affiliations: \\ ${ }^{1}$ Department of Curriculum \\ Studies, Stellenbosch \\ University, South Africa \\ Correspondence to: \\ Piera Biccard \\ Email: \\ pbiccard@yahoo.com \\ Postal address: \\ 652 16th Avenue, Rietfontein \\ 0084, South Africa \\ Dates: \\ Received: 06 Mar. 2011 \\ Accepted: 16 June 2011 \\ Published: 16 Sept. 2011 \\ How to cite this article: \\ Biccard, P., \& Wessels, \\ D. (2011). Development \\ of affective modelling \\ competencies in primary \\ school learners. Pythagoras, \\ 32(1), Art. \#20, 9 pages. \\ http://dx.doi.org/10.4102/ \\ pythagoras.v32i1.20
}

C 2011. The Authors.

Licensee: AOSIS

OpenJournals. This work

is licensed under the

Creative Commons

Attribution License.
Learner affect and beliefs about mathematics are complex and multifaceted aspects of mathematical learning. Traditional teaching and learning approaches in mathematics education often result in problematic beliefs about mathematics. Since beliefs influence what learners learn and how they deal with learning mathematics, it is essential that the roles of beliefs and affect in mathematics classrooms are carefully examined. In solving modelling problems, learners and teachers take on new roles in the classroom: learners are placed in an active, self-directing situation in which they solve real-world problems. When learners engage in modelling tasks, they display and integrate cognitive, meta-cognitive and affective competencies. A modelling approach therefore allows one to detect learner beliefs in an authentic learning environment. Will this environment lead to students having more positive and productive dispositions towards mathematics? This article presents partial results of a study documenting the development of modelling competencies in learners working in groups over a period of 12 weeks. Through a design research approach, 12 learners working in groups solved three modelling problems, and transcriptions of learner interactions, questionnaires and informal interviews revealed that learner beliefs improved over this short period when exposed to modelling tasks. The results are encouraging, and may provide mathematics education with an avenue to develop more positive learner beliefs in mathematics.

\section{Introduction}

Beliefs are a stable, affective response to mathematics (McLeod, 1992), which encompass an individual's understandings and feelings that shape the way they conceptualise and engage in mathematical activities (Schoenfeld, 1992). This means that beliefs as part of the affective domain do not function independently from the cognitive or meta-cognitive domains. If beliefs shape learner understanding in learning mathematics, then they should be considered an important part of mathematics education research. In fact, Cobb (1986, p. 4) states that beliefs are 'a crucial part of the assimilatory structures used to create meaning'.

This study accepts that beliefs 'are largely cognitive in nature and are developed over a relatively long period of time' (McLeod, 1992, p. 579), and since the 'cognitive and affective domains intersect in the area of beliefs' (Schoenfeld, as cited in McLeod, 1992, p. 590), this is a significant realm of research for understanding and improving mathematical learning. This statement assists in understanding that beliefs influence what is learnt by learners in mathematics classrooms as well as how it is learnt.

According to Walberg's (1984) theory of educational productivity, the following nine factors are considered to be 'potent, consistent and widely generalisable' (p. 20), and if optimised could develop learners' affective, behavioural and cognitive domains. The nine factors, divided into three groups, are as follows:

- Learner Personal factors: The learner's ability; age and stage of maturation; motivation and willingness to persevere.

- Instructional factors: The amount of time spent engaged in learning; the quality of the instructional experience including psychological and curricular aspects.

- Environmental factors: The learner's home; the learner's class social group; the peer group outside the school; and the learner's use of out of school time.

In the main study (Biccard, 2010) learners were involved in collaborative work on modelling tasks. This meant that one factor from each of Walberg's groups was directly affected by the programme. Learners were highly motivated during the programme; they spent more time on quality tasks, whilst the grouping focused on shared ideas and opinions. This was a change from the traditional approach to mathematics tasks that they had experienced.

Traditional teaching methods in mathematics classrooms have led to learners holding common negative beliefs about mathematics (Schoenfeld, 1992). This is because a traditional teaching 
approach focuses on drilling specific procedures - that are not necessarily meaningful to learners and which they do not always understand or relate to anything else in their lives. Traditional teaching is entrenched in what Ernest (1988) called an instrumentalist view of mathematics, which sees the subject as well defined and as a correct set of procedures that need to be practiced and memorised. Traditional teaching methods also have learners working individually, which according to Cobb (1986, p. 8) means they lose valuable feedback mechanisms that they would experience working with peers, such as dealing with inconsistencies, expressing concepts and comparing procedures.

Interaction assists learners to build a socially rich view of mathematics. Cobb (1986) therefore suitably defines learner beliefs about mathematics as their 'attempted solutions to problems that arise as they interact with the teacher and their peers' (p. 8). Cobb further clarifies that learner beliefs are not simply communicated from teacher to learner, but that students construct beliefs that fit into the classroom norms that they have experienced. In this sense, Cobb explained learner beliefs as both social and cognitive, developing in response to the learners' experience of classroom mathematics. Changes in classroom experiences may hinge around tasks set for the classroom. The hypothesis of this study is that interaction around good-quality tasks develops more positive beliefs about the value and use of mathematics in learners.

In the main study, the development of modelling competencies in primary school learners was documented over a period of 12 weeks. Three main areas of competence - cognitive, meta-cognitive and affective - were considered. Within the affective domain, it was decided to determine if a modelling perspective on learning mathematics could result in more positive beliefs being held by learners. Traditional classrooms tend to encourage rote learning and drilling of abstract concepts; very often problems are routine and removed from anything that resembles real-life problems. To change pupil perceptions and beliefs, problems set in real life are necessary. Modelling problems present real situations that need learner engagement and structuring. Very often modelling tasks result in a product that is different to traditional exercises (Lesh \& Doerr, 2003a, p. 16), often a letter or report to someone (a client) who has a real need for the problem to be modelled. This means that learners may experience mathematics as useful and connected to real-life problems and to real people who make decisions based on models.

In terms of the main study, the focus was on changing the quality of not only the teaching experience but what was considered to be the 'learning experience'. Modelling tasks require that learners work in groups, and much more time is needed to complete them because of their complex and real nature.

This study considered whether well-formulated modelling tasks in teaching could positively transform learner beliefs about mathematics. During the 12-week period that learners were involved in the modelling programme, positive results to support this hypothesis were found, which are presented in this article.

\section{Affective modelling competencies Aspects of affect and belief}

Mandler's view on affective factors (McLeod, 1992) is that learner emotions play a role when a sequence of actions cannot be carried out. Learner emotions also play a role when a sequence of actions can be played out, but negative emotions may be of a more lasting nature. Mandler proposes three aspects of affective experience. Firstly, learners do hold certain beliefs about mathematics, about how it should be taught and about the social context (often solitary and competitive) in which mathematical learning takes place. Secondly, according to McLeod, interruptions and blockages are an inevitable part of learning mathematics and learners will experience both positive and negative emotions - more noticeably during tasks that are novel. Thirdly, learners will develop a positive or negative attitude based on a repetition of certain emotional responses. This article specifically focuses on learner beliefs in the affective domain. It will be shown that learners involved in modelling tasks within a group environment encounter a positive emotional response that may lead to building more positive beliefs about mathematics.

Goldin's (2008, p. 188) view of affect is that it should be 'regarded as an internal representation system', and 'to see affect as representational is to hypothesize that emotions encode information'. He adds that it is 'detailed, contextdependent, rapidly changing information essential to the doing of mathematics'. To uncover learner-affective internal representations is not an easy task, but whilst modeling, learners do leave 'auditable trails of documentation' (Lesh \& Doerr, 2003a, p. 31). These are the many written and verbal products of learner interactions when modelling, which allow glimpses into what learners are thinking even on an affective level. This trail of documentation that learners produce whilst modelling allows a certain rendering of learner-affective factors not always possible with more traditional teaching approaches. As explained by Lesh and Doerr (2003a), problem-solving leads to significant forms of learning. This learning can also include affective learning or an awareness of the use and value of mathematics through tasks that would encourage learners to think mathematically. Lesh and Doerr further clarify that thinking mathematically involves constructing, describing, explaining, and making patterns in complex systems (2003a, p. 16). This suggests that the content of learners' mathematics classroom experiences may have an impact on the beliefs that learners would hold as a result of these experiences.

The relationship between experiences and beliefs is a premise for this study. If emotion encodes information, then all learning would have an affective element and all learning experiences would allow learners to formulate certain beliefs 
about mathematics. This means that learning through tasks such as modelling may enable learners to develop more positive beliefs about their abilities to interact successfully with mathematics, and more positive beliefs about the role of mathematics in real-life situations.

\section{Beliefs}

Definitions of 'beliefs' lead to discussion of knowledge and the nature of knowledge. Beliefs are considered to be the acceptance that something is true based on evidence. This means that learners hold certain beliefs if some evidence generated those beliefs. Beliefs that mathematics is about learning and memorising rules means that learners were given this evidence in their classrooms. Beliefs are different to knowledge, in that they include an affective component (Speer, 2005). Uncontested knowledge can be tested, whilst personally accepted knowledge which includes beliefs has a personal judgement facet to it. Beliefs may better be conceptualised as knowledge that has been reflected on from a personal perspective.

When learners become personally involved in their learning and reflect on this learning, then a formation of beliefs takes place. Learners develop beliefs about the role-players in the learning situation. They develop beliefs about themselves and their abilities and beliefs about the relevance of the subject matter to their lives and real problems in general. Learners also develop beliefs through the role and nature of content in the mathematics classroom experience.

Ernest (1998) reminds us that since the time of Plato, mathematical knowledge has been thought of as secure and infallible. This means that in a traditional classroom, mathematical knowledge is handed over from teacher to learner as absolute truths that learners have to memorise and learn to apply. From a modelling perspective, learners produce, sort out and develop conceptual tools that describe or explain a mathematically significant system (Lesh \& Doerr, 2003a, p. 9, 2003b, p. 532). When learners experience the former in their classrooms, their beliefs about mathematics may be very different to when they experience modelling in mathematics classroom activities. The learners involved in this study often used phrases such as 'your method', 'my method' or 'what did you do?', which showed more ownership of the problem than just memorising of rules.

Österholm (2009, p. 158) asked how knowledge of the relationship between the diameter and circumference of a circle is 'less' affective than beliefs about mathematics teaching. It may be that the latter is personally reflected knowledge and this adds the affective component, whilst the former is not personally reflected knowledge but knowledge that is accepted as true. It may be that knowledge is unlikely to be disputed, whilst beliefs are not consistent for all people: for any belief that may exist, a diametrically opposing view may also exist. Wilson and Cooney (in Speer, 2005 , p. 365) propose a different perspective than insisting on definitions for beliefs. In a study on teacher beliefs they stated that concerns over precise definitions of beliefs are not as important as issues of understanding teacher knowledge. Schoenfeld (2011, p. 52) establishes that beliefs are 'very powerful explanatory constructs'.

The aim of this article is to understand and provide an explanation for the development of learner beliefs relating to mathematics during a modelling programme, and not so much to provide new definitions for beliefs. Answers to the questions posed in a pre-modelling and post-modelling sessions indicate learner beliefs, and their responses are reported on. If learner beliefs do change as a result of modelling tasks, then it can be inferred that modelling provides learners with the evidence, experience and repetition they need to modify some of their beliefs. Furthermore, it can be inferred that if beliefs do change, then modelling provides learners with a means for personal reflection that leads to improved beliefs about mathematics.

\section{Beliefs and mathematics}

In his work on problem-solving, Schoenfeld (1987, p. 190) focused and elaborated on three related but distinct meta-cognitive categories: knowledge about own thought processes, which includes how accurate learners are in describing their own thinking; self-regulation, which includes how well learners keep track of what they are doing and how well they use the input from observations to guide their problem-solving actions; and beliefs and intuitions, which includes what ideas about mathematics learners bring to their work in mathematics and how these shape the way they do mathematics. This article focuses on the third category of learner beliefs and intuitions about mathematics.

Schoenfeld (1992, p. 359) lists typical learner beliefs about the nature of mathematics:

1. Mathematics problems have one and only one right answer. (S1)

2. There is only one correct way to solve any mathematics problem - usually the rule that the teacher has most recently demonstrated to the class. (S2)

3. Ordinary learners cannot expect to understand mathematics; they expect simply to memorise it, and apply what they have learned mechanically and without understanding. (S3)

4. Mathematics is a solitary activity, done by individuals in isolation. (S4)

5. Learners who have understood the mathematics they have studied will be able to solve any assigned problem in five minutes or less. (S5)

6. The mathematics learned in school has little or nothing to do with the real world. (S6)

These six categories relating to learner beliefs were used to code the data for this study. Although Schoenfeld generated these from work on problem-solving, whilst traditional teaching pervades schools, these categories are still relevant and can be used to code transcriptions of learner work whilst modelling. 
Goldin (2007, p. 289) states that affective competencies refer to a person's ability to use affect positively during a mathematical activity, and that future research should be devoted to studying how learners change global affective structures regarding mathematics. Goldin's concept of a global affective structure was also included as this concept extends the discussion on beliefs. Global affect refers to complicated affective structures which include emotions, beliefs, values, stories, memories and one's history. Goldin (2007, p. 289) further set out three essential affective structures which were also used to code data:

- Mathematical integrity (G1): This relates to learners being committed to truth and understanding in mathematical activities. This also relates to the learners' willingness to acknowledge that they do not understand something, their decision to take action and the nature of the action that the learner decides to take (DeBellis \& Goldin, 2006, p. 138).

- Mathematical self-identity (G2): This relates to the learners' personal sense of self in relation to mathematics. Goldin (2007, p. 291) explained that this is developed over time, incorporates a feeling of ownership or nonownership regarding mathematics, and involves a set of current possibilities relating to who the individual is relating to mathematics.

- Mathematical intimacy (G3): This can be associated with the concept of 'flow', which describes an experience that is engrossing and enjoyable to the extent that it is worth doing for its own sake (Csikszentmihalyi, 1999, p. 824). Csikszentmihalyi (1999) describes some of the conditions that make flow in an activity possible: it should allow one the feeling of being separate from the routines of everyday life, be so demanding that little attention is left for irrelevant stimuli, have clear goals every step of the way (either set by the person or the activity itself), provide immediate feedback on what is being done, and enable one to balance skills with the challenge at hand.

Beliefs seem to form the underlying core of these affective structures, although these structures are more holistic than learner beliefs. These affective structures were used for coding the data to trace affective competency development. Both Schoenfeld's and Goldin's categories could be used to analyse learner beliefs whilst they are engaged in a modelling task. It may be valuable to use existing concepts and categories to code data on modelling: Schoenfeld's categories focus specifically on typical learner beliefs, whilst Goldin's categories were used to focus on more widespread affective facets of learning.

\section{Modelling and models}

A modelling task results in learners producing a model to solve a task. The explanation of a model is taken from Lesh and Doerr (1998), who state that a model is a scheme that describes a (real-life) system, that assists in thinking about that system, making sense of it or making predictions. A model consists of elements, relationships, operations that describe how the elements interact, and patterns or rules that apply to the preceding relations or operations. A model focuses on the underlying structural characteristics of a real-life system being described. Therefore a model can be a description, explanation or prediction of a real-life situation.

From the above, it is apparent that modelling is very different to traditional mathematics tasks. Modelling requires a larger domain of cognitive, meta-cognitive and affective competencies than traditional tasks. The process that learners go through when modelling is displayed in a normative modelling cycle in Figure 1.

Modelling is more complex than traditional tasks (Chamberlin \& Moon, 2005; Lesh \& Doerr, 2003a). In a traditional classroom learners remain at a single node of the cycle - working mathematically, whilst the teacher or textbook is responsible for the rest of the cycle. From this experience learners could develop negative beliefs about what mathematics is, how it is learnt and how it is relevant to real life.

Once learners are placed in a directorship role of the entire cycle, their beliefs about mathematics should start to change. Initially their negative beliefs leave them frustrated and they try to solicit a traditional 'didactical contract' (Brousseau, 1997, p. 39) by asking the teacher to show them the method or solution. Blomhoj and Jensen (2007) describe a key to modelling as learning to cope with feelings of 'perplexity due to too many roads to take and no compass given' (p. 49). This type of perplexity is not easily overcome. As learners gain experience of modelling, they are able to develop their modelling competencies. By modelling, learners are responsible for wider aspects of problem-solving, which changes their experiences, and this may result in a change in affective competencies. Modelling tasks also provide learners with evidence that mathematics is useful and that

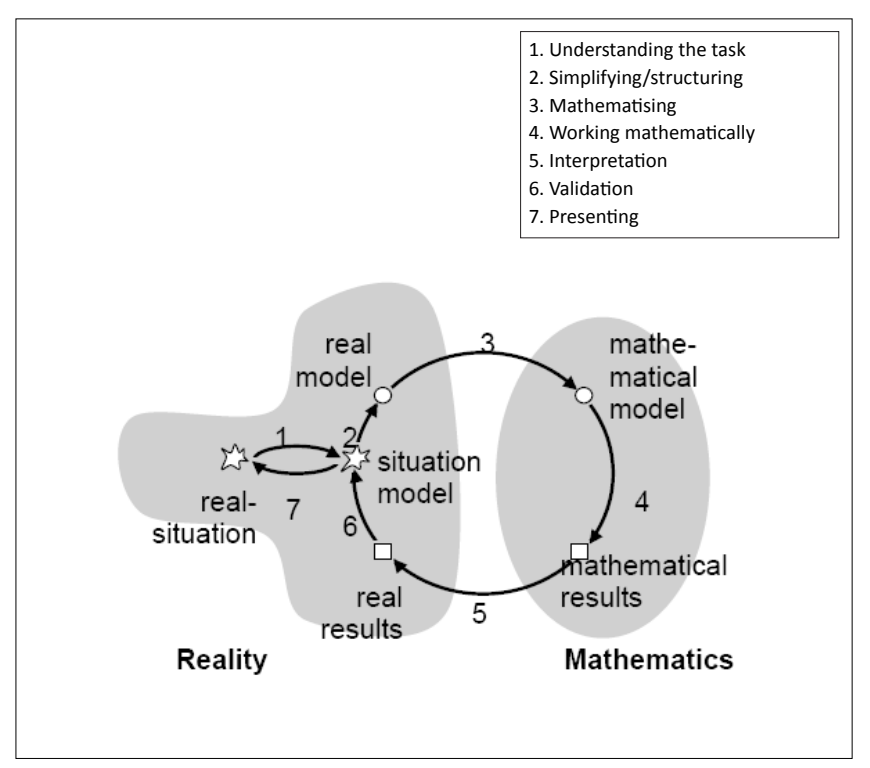

Source: Borromeo Ferri, R. (2006). Theoretical and empirical differentiations of phases in the modeling process. Zentralblatt fur Didaktik der Mathematik (ZDM): The International Journal on Mathematics Education, 38(2), 86-95.

FIGURE 1: A modelling cycle. 
they can use mathematics to solve problems. With modelling tasks, groups of learners negotiate meaning with each other and create a model for the situation in their own way without any predetermined, memorised methods.

\section{Modelling competencies Cognitive, meta-cognitive and affective modelling
competencies}

In the main study (Biccard, 2010) the nodes of the cycle were termed modelling competencies and explored as learners modelled three problems over a period of three months. There are, however, other competencies necessary for learners to model successfully. Included are not only cognitive competencies, but important domains of meta-cognitive and affective competencies. The following cognitive modelling competencies were considered in the main study (see Figure 1): understanding, simplifying, mathematising, working mathematically, interpreting, validating, presenting and arguing. Meta-cognitive competencies that were included were: planning and monitoring, a 'sense of direction' (Treilibs, Burkhardt \& Low, 1980, p. 52) and using informal knowledge (Mousoulides, Sriraman \& Christou, 2007 , p. 39). From the realm of affective competencies, beliefs were selected.

Competence is taken from Weinert's definition (Henning \& Keune, 2007, p. 225), as the sum of available abilities and skills and the willingness of a learner to solve a problem and to act responsibly concerning the solution. Modelling competencies encompass all the abilities and skills a learner uses in solving a modelling problem. A learner employs these abilities and skills together with certain beliefs, and these beliefs affect the way in which the learner may successfully use available abilities and skills. McLeod (1992, p. 578) also identified beliefs as a concept in the affective field that is more stable than emotions or attitudes. This was an indication that beliefs could be considered a competency. Beliefs were included as a competency so that an awareness or development/change in learner beliefs could be monitored together with the other competencies that were identified. Since the instrument did not use Likert-type scales but a qualitative open coding, the development of learner beliefs as a natural progressing entity could be documented before and after a modelling programme.

Beliefs as an element of affect play an important role in learning and are a consequence of learning experiences. The relationship between teaching approaches and beliefs has been established (Spangler, 1992). Since this cycle is not easily broken, the focus of research should then be on using the teaching approach-beliefs cycle and not working at breaking the cycle. If the relationship between teaching and beliefs about mathematics exists, then changing instruction to a modelling approach may lead to more positive beliefs about what mathematics is, how it is learnt and how it is relevant to real life.
Beliefs are a stable, affective construct developed over a long period of time. However, Harel and Lesh (2003) show that during 90 minutes of modelling, the stages of learner thinking are strikingly similar to those described by van Hiele (1986, cited in Harel \& Lesh, 2003) or Piaget (1958, cited in Harel \& Lesh, 2003). These 'compact versions of developmental sequences' (Harel \& Lesh, 2003, p. 381) assisted in hypothesising that learner beliefs may also develop over a relatively short period of time whilst they are involved with modelling tasks.

\section{Research design}

\section{Research method}

A design research paradigm was followed for the main study. The design phase included the preparation of tasks and instruments. The teaching experiment involved contact sessions between the researcher and the learners, whilst ongoing analysis of data allowed for changes to be made to the design of subsequent modelling sessions. Bakker (2004) gives a detailed description of the three phases of the design research approach, that is, design, the teaching experiment and retrospective analysis.

\section{Participants}

Twelve Grade 7 learners were selected for the study and worked in three groups with four learners in each group. These learners attend a well-resourced suburban primary school. The groups comprised equal numbers of girls and boys and included various population groups. The groups were purposively selected and comprised two groups of learners who were 'weak' in mathematics (Groups 1 and 3) and one group who were 'strong' in mathematics (Group 2). The selection was based on learners' school results. Part of the results of the full study included comparing the development of modelling competencies in weak and strong learners. Learner ages ranged from 11 to 13 years. They worked for 12 weeks solving three modelling problems.

\section{Contact sessions}

Learners met with the first author weekly after school hours for sessions of approximately one hour. These sessions were audio-recorded and transcribed, whilst the sessions where learners presented their solutions were video-recorded. The researcher also kept a book of field notes. All learners' written work was kept and analysed. Informal interviews with groups were recorded and transcribed. Each task required approximately four sessions, which included a report-back session. All groups completed all three tasks. These learners had not been exposed to modelling problems before. The groups worked autonomously whilst the researcher moved between the three groups, acting as soundboard and listener, posing questions from time to time.

\section{Tasks}

The tasks used were sourced from existing modelling literature and all related to proportional reasoning. Box 1 provides a précis of the three tasks the groups worked on. 
BOX 1: The three modelling tasks.

Task 1: Big Foot (Lesh, Hoover \& Kelly [1992])

Supporting material: Example of footprint (size 24). Groups had to model how to find the height or size of this person and also provide a toolkit on how to find anyone's height or size from their footprint.

Task 2: Catalogue Problem (Lesh, Hoover, Hole, Kelly \& Post [2000])

Supporting information: Catalogue prices from 1999 and 2009. Groups had to assist another learner who had written a letter stating that his pocket money is the same as his sister's was 10 years ago. He needed assistance in convincing his parents that he needed more. They also had to provide an amount with suitable reasons.

Task 3: Quilting Problem (Lesh \& Carmona [2003])

Groups were given a quilt pattern together with the size of the completed quilt. They had to provide the correct pattern pieces together with cutting and stitching guides.

Note: Please see the full reference list of this article, Biccard, P., \& Wessels, D. (2011) Development of affective modelling competencies in primary school learners. Pythagoras, 32(1), Art. \#20, 9 pages. http://dx.doi.org/10.4102/pythagoras.v32i1.20, for more information

\section{Data collection and data processing}

Learners completed a pre-modelling questionnaire before they started working on the modelling tasks. The questionnaire included questions on what learners believe mathematics is all about, what they enjoy about mathematics and where they find mathematics relevant in everyday life. Learners answered another questionnaire after the 12week session. All contact sessions were audio-recorded and transcribed. Learners had to complete a number of progress documents each week. Their informal written work was also scrutinised. At the end of each task learners presented their solutions to the other groups involved in the study.

Data were coded for all the competencies identified for the main study, and specifically according to Schoenfeld (1992) and Goldin (2007) for affective competencies. Findings in terms of learner growth in affective modelling competencies are presented in the 'Results' section.

\section{Reliability}

The tasks used in this study were sourced from existing literature by experienced researchers in modelling, which meant that the responses and models produced by learners were consistent with existing research. However, this study also considered the development of modelling competencies and did not consider the tasks in isolation. Transcriptions were made by the first author on the same day as the session was held, and could therefore be used in conjunction with the first author's field notes. The study involved three groups, and the results being consistent across the three groups added to the reliability of the study. The findings of the study are not contrary to those in other studies, and as such the reasonableness of the inferences (Bakker, 2004) is continuous.

\section{Validity}

Direct participant transcriptions added to the validity of the study, as did the recorded data and hard copies of transcriptions. The use of two coding systems (those of Schoenfeld [1992] and Goldin [2007]) for the data also added to the validity of the study, as did the use of numerous data sources (learner work, audio-recordings of modelling sessions, video-recording of presentation sessions, questionnaires and informal interviews).

\section{Ethical considerations}

Permission for the study was granted by the Gauteng Department of Education, the participating school as well as the affiliated university. Parents of learners selected for the study were briefed as to the aims and objectives of the study and gave consent for their children to be involved. Learners participated in the study voluntarily. The aims and objectives of the study were discussed with learners and they were allowed to ask questions. The name of the school and those of the learners were not divulged. The recordings, transcriptions and learner work were stored away safely by the first author.

\section{Results}

The first part of this discussion relates to Schoenfeld's categorisation (S1-S6) of learner beliefs, whilst in the second part Goldin's affective structures (G1-G3) are used to mould the discussion. The selected excerpts from transcriptions highlight a healthy view of the nature of mathematics and an awareness of the use and value of mathematics. Since beliefs are built over a long period of time, it may be possible that the tasks provided learners with evidence that may begin a change in their beliefs about mathematics.

Learner ideas about what constitutes a mathematical task form part of their beliefs. Group 2 had the following discussion after a heated argument in Task 3, that can be related to beliefs about mathematics and the nature of mathematical tasks (in the following protocols, letters denote the names of different children):

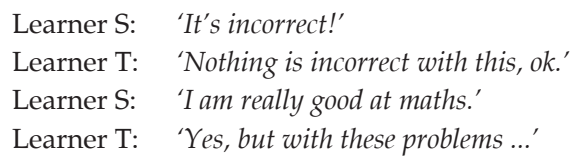

(Biccard, 2010, p. 124)

Here Learner $\mathrm{T}$ is moving towards changing beliefs about mathematics problems, but Learner $S$ remains unchanged, holding that 'I am really good at maths'. This shows that Learner $\mathrm{T}$ may have been becoming more aware of a difference between these problems and traditional tasks.

In learners' written reports after each session, they had to write down where they needed assistance. Group 3 wrote this after the first session of Task 1 :

What we need help with? [Learner E]

To get the thing right, to plus it or to divide it or whatever. [Learner M]

This shows that the learners expected to apply some mathematics that they knew, without really understanding what they were doing (S3).

By Task 3, they were discussing how to find a ratio, with the focus on their own understanding of the task (development of S3): 
Learner G: 'We need to find something related to that.' [Pattern measurement and real measurement.]

Learner E: 'We need to measure this which is 27,4 ... now we need to find something that will give us ... something that is ...'

Learner M: 'Related ... We are trying to see our answer.'

Learners were informally interviewed during Task 2, when they were asked by the researcher about their experience of working in groups as opposed to working individually (S4) and both groups responses are given in Box 2 .

By the end of Task 3 , the following comments were made by Group 3, showing a gradual change in their beliefs about the nature of mathematical tasks (Development of S5):

The thing about the beginning of a task is that we are always so confused. [Learner G]

That's impossible. Look, I don't think we are going to get a direct answer at the very beginning of a task. [Learner G]

No, we'll never do that, unless we have a time machine. [Learner $\mathrm{W}]$

(Biccard, 2010, p. 125)

The problems involved a large amount of reading, which is not common in traditional classrooms. Since real problems are set in a context that needs to be understood, often through reading, learner response to reading the supporting material for each task allowed S6 to be gauged. During Task 1 , the learners were unsure what all the reading material was about, as one indicated by saying 'I don't think the teacher meant for us to read this stuff'.

This shows that they may not have believed that mathematics problems involved much reading. However, by Task 3 they did not question the supporting material for each task, but simply referred to it when they needed to:

Learner S: 'This problem is a little more serious than the last. Oh well, what the heck, let's give it a try. How do we start the problem A?'

Learner A: 'Ok. Read this.'

Learner J: 'Do you think we have to make this outside also?'

Learner A: 'No, that is a photo frame.'

Learner J: ' Read what we are asked to do. Just read it again ...'

Evidence was found, which includes elements from S1-S6, that learners believe that mathematics must be done neatly and that whole number answers are more 'correct' than messy decimals. An incident showing that learners viewed mathematics as a neat, systematic endeavour is noted at a later stage, and is also mentioned as it directly affected Group 3's modelling competencies. It was noticed that Group 3 spent

BOX 2: Learner responses when asked about their experience of working in groups as opposed to working individually.

\begin{tabular}{|c|c|}
\hline $\begin{array}{l}\text { Group } 1 \\
\text { Researcher: } \\
\text { Learner } \mathrm{N} \text { : } \\
\text { Learner } \mathrm{M} \text { : }\end{array}$ & $\begin{array}{l}\text { 'Why do you need the group?' } \\
\text { 'Because if one idea doesn't work ... everybody's idea together.' } \\
\text { 'All ideas become a better idea.' }\end{array}$ \\
\hline \multicolumn{2}{|l|}{ Group 2} \\
\hline Researcher: & 'Is it nicer to work in a group or on your own, or does it depend?' \\
\hline Learner A: & 'I like it in a group.' \\
\hline Learner $\mathrm{T}:$ & 'We can talk.' \\
\hline Learner J: & 'It wouldn't be nice to work on my own.' \\
\hline
\end{tabular}

a lot of time rewriting a list of items from a catalogue for Task 2 (Catalogue Problem), and lost valuable time doing this. The next week, they were questioned about their decision:

Researcher: 'Why did you write the prices over? When they were here?' [on the instruction sheet provided] 'Was there a reason?'

Learner M: [A little embarrassed] 'We didn't want to mess the page.'

(Biccard, 2010, p. 124)

During Task 2, Group 2 noticed that they had reached an answer of a whole number. This led them to think that they must be on the right track. They still assumed that neat, round numbers were more correct than decimal numbers, and Learner J exclaimed '[b]ut ours and yours adds up to R200 [exactly], there is a connection!' (Biccard, 2010, p. 124).

By Task 3, this group worked with a decimal of up to 5 digits without thinking that it was incorrect.

When looking at Goldin's essential affective structures, it was found that modelling elicits the affective structures he describes. Mathematical integrity as an affective structure includes an awareness of one's limitations in understanding and acknowledging them and working towards removing them (Goldin, 2007). This structure is strongly affective and confirms learner beliefs in mathematics and their experiences of it. It was found that learners were unafraid to acknowledge their confusion or frustration with these tasks - which is largely kept silent during traditional instruction. If it is evident, the teacher feels responsible for clearing up the confusion due to the didactical contract (Brousseau, 1997) that exists. With modelling tasks learners had to support and provide scaffolding for each other. The following condensed excerpt illustrates the need for mathematical integrity (G1) that modelling elicits (Task 1 ):

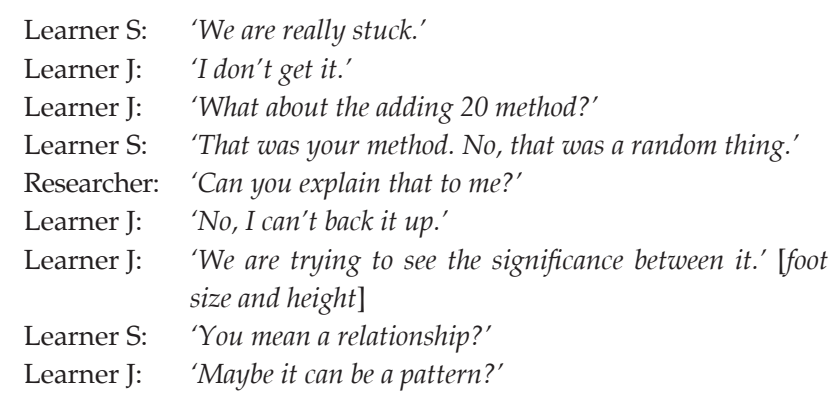

The input from learners corresponded with mathematics self-identity (G2) are listed in Box 3.

Learners were slowly starting to place themselves, their thoughts and values into the mathematical arena, which resulted in a much fuller mathematical experience.

The following highlights mathematical intimacy (G3), which includes a 'vulnerable interaction involving one's sense of self during mathematical activity' (Goldin, 2007, p. 291); the final question on the questionnaire asked for any comments the learners wished to offer, and a number of learners stated: 'When are we going to do this again?'

The following comment by one learner fits into Csikszentmihalyi's concept of flow: 'I did enjoy the problems 
BOX 3: The questions and answers from learners in Group 2 on mathematics self-identity.

\begin{tabular}{|c|c|}
\hline \multicolumn{2}{|c|}{$\begin{array}{l}\text { Question (from questionnaires): What did you learn whilst working on the task? } \\
\text { (Task 2) }\end{array}$} \\
\hline $\begin{array}{l}\text { Learner } \mathrm{M} \text { : } \\
\text { Learner } \mathrm{E}:\end{array}$ & $\begin{array}{l}\text { 'I should get a higher allowance!' } \\
\text { 'I learnt that when I really think about something, I get a whole } \\
\text { lot of ideas in my head but I don't know how to explain it.' }\end{array}$ \\
\hline \multicolumn{2}{|c|}{ Question: What do you believe mathematics is all about? } \\
\hline $\begin{array}{l}\text { Learner } \mathrm{N} \\
\text { (pre-modelling): } \\
\text { Learner } \mathrm{N} \\
\text { (post-modelling): }\end{array}$ & $\begin{array}{l}\text { 'Maths is about sums that you should know.' } \\
\text { 'Learning how the sums work and finding the right answers.' }\end{array}$ \\
\hline \multicolumn{2}{|c|}{ Question: What 'outside' information did you use to solve the task? (Task 2) } \\
\hline Learner G: & $\begin{array}{l}\text { 'I used my general knowledge of fairness and knowing how } \\
\text { people would react.' }\end{array}$ \\
\hline \multicolumn{2}{|c|}{ Question: What did you learn about mathematics during the programme? } \\
\hline Learner $\mathrm{N}$ : & $\begin{array}{l}\text { 'That we could find the real answers in real life by adding, } \\
\text { subtracting, scaling down/up.' }\end{array}$ \\
\hline Learner E: & $\begin{array}{l}\text { 'I learned that there are many different ways to use } \\
\text { mathematics.' }\end{array}$ \\
\hline Learner T: & $\begin{array}{l}\text { 'I learnt that maths can even be used when sewing a quilt } \\
\text { together.' }\end{array}$ \\
\hline Learner T: & $\begin{array}{l}\text { 'Mathematics is not always practiced but it is used in our } \\
\text { everyday lives.' }\end{array}$ \\
\hline
\end{tabular}

Source: Biccard, P., \& Wessels, D.C.J. (2011). Documenting the development of modelling competencies of grade 7 mathematics students. In G. Kaiser, W. Blum, R. Borromeo Ferri, \&
G. Stillman (Eds.), Trends in teaching and learning of mathematical modeling (pp. 375-384). G. Stillman (Eds.), Trends in teaching and learning of mathematical modeling (pp. 375-384
Dordrecht, Netherlands: Springer. http://dx.doi.org/10.1007/978-94-007-0910-2_37

because you got to go way out of the ordinary and when you're done you feel so fantastic'.

Affective structures and beliefs are brought to light whilst learners are involved in modelling tasks, which allow one to view learner beliefs and affective structures formed over the entire span of learner experiences with mathematics. Modelling therefore fulfills two different but mutually important roles: it serves as a mirror in which learners reflect not only their mathematical knowledge and skills but also their affective orientations, and also suitably fills the role of generating an environment within which to build more positive beliefs about mathematics.

\section{Discussion}

Goldin's view (2007, p. 293) that 'mathematical modelling activity itself brings about not only cognitive development, but development of the affective system' is accepted by the authors by virtue of the results of this study. Learner affective competencies seem to be 'far more complex than one might infer from just the surface consideration of emotional feelings' (Goldin, 2007, p. 281). The results point to the idea that learners can undergo 'global affective changes' (Goldin, 2007 , p. 293). What is important to note is that a relatively short modelling course facilitated a shift in some learner beliefs.

McLeod's (1992) view that what is needed is a change in the curriculum that fosters learners' negative beliefs is also accepted. Modelling allows for such a change or modification to both the curriculum and teaching strategies. Possibly, as suggested by Wilkins and Ma (2003), recognition of negative trends is a central first step for teachers in attempting to reverse negative learner beliefs. As such, these results are concurrent with the findings of Wilkins and Ma (2003), in that exposing learners to challenging mathematics may curb the development of negative beliefs about mathematics.

Returning to Walberg's (1984) model of productivity (p. 21), modelling affects at least one factor in each of the three main areas. With regard to learners' personal factors, modelling increases learner motivation. Modelling also makes significant changes to the teaching factors by improving the quality and amount of time spent on the learning experience, and affects environmental factors by making changes to the traditional classroom environment and interaction.

Modelling allows Mandler's affective aspects (McLeod, 1992) to come into view. Within the modelling sessions learners did hold certain beliefs about mathematics, and some of these beliefs showed signs of positive change towards the end of the programme. Learner blockages were evident - and so were their routes through these blockages; it was their use of informal methods through these blockages that built more positive beliefs about mathematics. In order to maintain or consolidate these positive attitudes, repetition of these tasks is necessary.

Modelling as a teaching approach in mathematics classrooms will lead to learners using their own (often invented) methods and allow learners to mathematise situations in ways that are meaningful to them. Learners are not expected to follow a rehearsed method or a set procedure (that they often do not understand). The model that results from engaging in a wellformulated modelling task is constructed by learners and shows their understanding of the problem situation.

In Perrenet and Taconis' (2009) study, that showed significant shifts in the beliefs of university students, the students were asked to explain their own shift in beliefs to point out differences between their secondary school and university mathematics experiences. According to these students, the difference was in the nature of the problems that they were given to solve. They said that school problems were standard closed problems, whilst those at university were more challenging and complex. Goldin (2007, p. 294) affirms that teacher-guided modelling produces long-term effects that have cognitive and affective consequences.

Modelling as an environmental factor allows learners to work in groups, collaborating with each other. From a socioconstructivist view, affective processes are considered an essential part of problem-solving and learning (Op't Eynde, De Corte \& Verschaffel, 2006) so they form a key part of a modelling environment and are also developed through this environment. From a social-interactionist lens, individuals construct meaning through social interaction but, more importantly, social interaction is the process that forms learner conduct and is not simply a setting for this conduct to take place (Yackel, 2000). Social interaction therefore forms learner beliefs about mathematics. This too was evident in the study. 
Goldin's (2007) view that 'adequate foundations for studying and enhancing mathematical learning and development must incorporate the affective domain - not as an architectural add-on, but as a structurally essential building block' (p. 281) provides encouragement to further research affective factors in mathematics learning.

\section{Acknowledgements}

The financial assistance of the National Research Foundation (NRF) towards this research is hereby acknowledged. Opinions expressed and conclusions arrived at are those of the authors and not necessarily to be attributed to the NRF.

The input and suggestions of the reviewers are acknowledged and the authors would like to thank them for their contribution.

\section{Competing interests}

The authors declare that they have no financial or personal relationships which may have inappropriately influenced them in writing this article.

\section{Authors' contributions}

This article presents partial results from a larger study in which P.B. conducted the research whilst D.W. supervised the study. This article from the main study was planned as a team. The manuscript was exchanged several times between authors. D.W. gave valuable insights as the article developed and unfolded.

\section{References}

Bakker, A. (2004). Design research in statistics education - On symbolizing and computer tools. Amersfoort: Wilco.

Biccard, P. (2010). An investigation into the development of mathematical modelling competencies of Grade 7 learners. Unpublished master's dissertation. University of Stellenbosch, Stellenbosch, South Africa. Available from http://hdl.handle. net/10019.1/5301

Biccard, P., \& Wessels, D.C.J. (2011). Documenting the development of modelling competencies of Grade 7 mathematics students. In G. Kaiser, W. Blum, R. Borromeo Ferri, \& G. Stillman (Eds.). Trends in teaching and learning of mathematical modelling (pp. 375-384). Dordrecht, Netherlands: Springer. http:// dx.doi.org/10.1007/978-94-007-0910-2_37

Blomhoj, M., \& Jensen, T.H. (2007). What's all the fuss about competencies? In W. Blum, P. Galbraith, H. Henn, \& M. Niss (Eds.), Modelling and applications in mathematics education. 14th ICMI study (pp. 45-57). New York: Springer. http:// mathematics education. 14th/10.1007/978-0-387-29822-1_3

Borromeo Ferri, R. (2006). Theoretical and empirical differentiations of phases in the modelling process. Zentralblatt für Didaktik der Mathematik (ZDM): The International Journal on Mathematics Education, 38(2), 86-95. http://dx.doi. org/10.1007/BF02655883

Brousseau, G. (1997). Theory of didactical situations in mathematics. Didactique des mathematiques 1970-1990. Netherlands: Kluwer Academic Publishers.

Chamberlin, S.A., \& Moon, S.M. (2005). Model-eliciting activities as a tool to develop and identify creatively gifted mathematicians. The Journal for Secondary Gifted Education, XVII, 1, 37-47.

Cobb, P. (1986). Contexts, goals, beliefs, and learning mathematics. For the Learning of Mathematics, 6(2), 2-9. Available from http://www.jstor.org/stable/40247805

Czikszentmihalyi, M. (1999). If we are so rich, why aren't we happy? American Psychologist, 54(10), 821-827. http://dx.doi.org/10.1037/0003-066X.54.10.821

DeBellis, V.A., \& Goldin, G.A. (2006). Affect and meta-affect in mathematical problem solving: A representational perspective. Educational Studies in Mathematics, 63, 131-147. http://dx.doi.org/10.1007/s10649-006-9026-4

Ernest, P. (1988, August). The impact of beliefs on the teaching of mathematics. Paper presented at the 6th International Congress on Mathematical Education, Budapest, Hungary.

Ernest, P. (1998). Social constructivism as a philosophy of mathematics. Albany: State University of New York Press.
Goldin, G.A. (2007). Aspects of affect and mathematical modeling processes. In R.A Lesh, E. Hamilton, \& J.J. Kaput (Eds.), Foundations for the future in mathematics education (pp. 281-296). Mahwah: Lawrence Erlbaum Associates.

Goldin, G.A. (2008). Perspectives on representation in mathematical learning and problem solving. In L. English (Ed.), Handbook of international research in mathematics education (2nd edn.) (pp. 176-201). New York: Taylor and Francis.

Harel, G., \& Lesh, R. (2003). Local conceptual development of proof schemes in a cooperative learning setting. In R. Lesh, \& H.M. Doerr (Eds.), Beyond constructivism. Models and modeling perspectives on mathematics problem solving, learning and teaching (pp. 359-382). Mahwah: Lawrence Erlbaum Associates.

Henning, H., \& Keune, M. (2007). Levels of modelling competences. In W. Blum, P.L. Galbraith, H.-W. Henn, \& M. Niss (Eds.), Modelling and applications in mathematics education. 14th ICMI study (pp. 225-232). New York: Springer. http://dx.doi. org/10.1007/978-0-387-29822-1_23

Lesh, R., \& Carmona, G. (2003). Piagetian conceptual systems and models fo mathematising everyday experiences. In R. Lesh, \& H.M. Doerr (Eds.), Beyond constructivism: Models and modeling perspectives on mathematics problem solving, learning and teaching (pp. 71-96). Mahwah: Lawrence Erlbaum Associates.

Lesh, R., \& Doerr, H.M. (1998). Symbolizing, communicating and mathematising: Key concepts of models and modeling. In P. Cobb, E. Yackel, \& K. McClain (Eds.) Key concepts of models and modeling. In P. Cobb, E. Yackel, \& K. McClain (Eds.),
Symbolizing and communicating in mathematics classrooms (pp. 361-394). Symbolizing and communicating in math
Mahwah: Lawrence Erlbaum Associates.

Lesh, R., \& Doerr, H.M. (2003a). Foundations of a models and modeling perspective on mathematics teaching, learning, and problem solving. In R. Lesh \& H.M. Doer (Eds.), Beyond constructivism: Models and modeling perspectives on mathematics problem solving, learning and teaching (pp. 3-33). Mahwah: Lawrence Erlbaum Associates.

Lesh, R., \& Doerr, H.M. (2003b). In what ways does a models and modeling perspective move beyond constructivism? In R. Lesh \& H.M. Doerr (Eds.), Beyond constructivism: Models and modeling perspectives on mathematics problem solving, learning and teaching (pp. 519-556). Mahwah: Lawrence Erlbaum Associates.

Lesh, R., Hoover, M., Hole, B., Kelly, A., \& Post, T. (2000). Principles for developing thought-revealing activities for learners and teachers. In A. Kelly \& R. Lesh (Eds.), Research design in mathematics and science education (pp. 591-646). Mahwah Lawrence Erlbaum Associates.

Lesh, R., Hoover, M., \& Kelly, A. (1992). Equity, assessment, and thinking mathematically: Principles for the design of model-eliciting activities. In I. Wirszup \& R. Streit (Eds.), Developments in school mathematics around the world. Vol \& R. Streit (Eds.), Developments in school mathematics around the world. Vol
3. Proceedings of the Third UCSMP International Conference on Mathematics 3. Proceedings of the Third UCSMP International Conference on Mathematics
Education, 30 October - 01 November 1991 (pp. 104-129). Reston: National Education, 30 October - 01 Novem
Council of Teachers of Mathematics.

McLeod, D.B. (1992). Research on affect in mathematics education: A reconceptualization. In D.A. Grouws (Ed.), Handbook of research on mathematics reconceptualization. In D.A. Grouws (Ed.), Handbook of researc
teaching and learning (pp. 575-596). New York: Macmillan.

Mousoulides, N., Sriraman, B., \& Christou, C. (2007). From problem solving to modelling - The emergence of models and modelling perspectives. Nordic Studies in Mathematics Education, 12(1), 23-47.

Op't Eynde, P., De Corte, E., \& Verschaffel, L. (2006). "Accepting emotional complexity": A socio-constructivist perspective on the role of emotions in the mathematic classroom. Educational Studies in Mathematics, 63, 193-207. http://dx.doi. org/10.1007/s10649-006-9034-4

Österholm, M. (2009). Beliefs: A theoretically unnecessary construct? In Proceedings of CERME6, 28 January - 01 February 2009. Working Group 1. Lyon, France: Institut National de Recherche Pédagogique (National Institute for Educationa Research). Retrieved August 06, 2010, from http://www.inrp.fr/publications/ edition-electronique/cerme6/wg1-13-osterholm.pdf

Perrenet, J., \& Taconis, R. (2009). Mathematical enculturation from the learners' perspective: Shifts in problem-solving beliefs and behaviour during the bachelor programme. Educational Studies in Mathematics, 71, 181-198. http://dx.doi. org/10.1007/s10649-008-9166-9

Schoenfeld, A.H. (1987). What's all the fuss about metacognition? In A. Schoenfeld (Ed.), Cognitive science and mathematics education (pp. 189-215). Hillside: Lawrence Erlbaum Associates Publishers.

Schoenfeld, A.H. (1992). Learning to think mathematically: Problem solving, metacognition and sense making in mathematics. In D.A. Grouws (Ed.), Handbook of research on mathematics teaching and learning (pp. 334-370). New York: Macmillan.

Schoenfeld, A.H. (2011). How we think: A theory of goal-orientated decision making and its educational applications. New York: Routledge.

Spangler, D.A. (1992). Assessing learners' beliefs about mathematics. The Mathematics Educator, 3(1), 19-33. Available from http://math.coe.uga.edu/tme/Issues/ v03n1/5spangler.pdf

Speer, N.M. (2005). Issues of method and theory in the study of mathematics teachers' professional and attributed beliefs. Educational Studies in Mathematics, teachers' professional and attributed beliefs. Educational Studie
58, 361-391. http://dx.doi.org/10.1007/s10649-005-2745-0

Treilibs, V., Burkhardt, H., \& Low, B. (1980). Formulation processes in mathematical modelling. Nottingham: Shell Centre for Mathematical Education.

Walberg, H.J. (1984). Improving the productivity of America's schools. Educationa Leadership, May, 19-27.

Wilkins, J.L.M., \& Ma, X. (2003). Modelling change in learner attitude toward beliefs about mathematics. Journal of Educational Research, 97(1), 52-63. http://dx.doi. org/10.1080/00220670309596628

Yackel, E. (2000). Creating a mathematics classroom environment that fosters the development of mathematical argumentation. Paper prepared for Working Group 1: Mathematics Education in Pre and Primary School of the Ninth International Congress of Mathematical Education, Tokyo/Makuhari, Japan. 